\title{
COMPENSATION AS MORAL REPAIR AND AS MORAL JUSTIFICATION FOR RISKS
}

\author{
A COMPENSAÇÃO COMO REPARAÇÃO MORAL E COMO \\ JUSTIFICAÇÃO MORAL DOS RISCOS
}

\author{
Madeleine Hayenhjelm* \\ madeleine.hayenhjelm@umu.se
}

\begin{abstract}
Can compensation repair the moral harm of a previous wrongful act? On the one hand, some define the very function of compensation as one of restoring the moral balance. On the other hand, the dominant view on compensation is that it is insufficient to fully repair moral harm unless accompanied by an act of punishment or apology. In this paper, I seek to investigate the maximal potential of compensation. Central to my argument is a distinction between apologetic compensation and non-apologetic compensation. Apologetic compensation, I argue, is an act that expresses regret and apology by means of some offer of money, goods, or services. Non-apologetic compensation is an act that seeks to restore loss or harm without expressing regret or apology. In the paper, I defend the view that acts of compensation can be apologetic and argue that such apologetic compensation is sufficient for moral repair.
\end{abstract}

Keywords: compensation, apologies, reparations, restitution, moral repair.

Sumário. Será a compensação capaz de reparar o dano moral causado por um acto errado anterior? Por um lado, há quem defina a função da reparação como reposição do equilíbrio moral. Por outro, a perspectiva dominante acerca da compensação considera que esta é insuficiente para reparar totalmente o dano moral a não ser que seja acompanhada de um acto de castigo ou de um pedido de desculpas. Neste artigo procuro investigar o potencial máximo da compensação. Uma distinção entre compensação apologética e compensação não apologética é central para o meu argumento. A compensação apologética é um acto que exprime arrependimento e um pedido de desculpas através de uma oferta de dinheiro, bens ou serviços. A compensação não apologética é um acto que procura restaurar a perda ou dano sem exprimir arrependimento ou um pedido de desculpas. Neste artigo, defendo a perspectiva segundo a qual os actos de compensação podem ser apologéticos e argumento que uma compensação apologética deste tipo é suficiente para a reparação moral.

Palavras-chave: compensação, pedidos de desculpas, reparações, restituição, reparação moral.

* Senior lecturer (associate professor) at the Department of Historical, Philosophical and Religious Studies, Umeå University. 


\section{o. Introduction}

In this paper, I am interested in whether something we might refer to as the strong compensation claim can be defended. This is the claim that full compensation is sufficient to right wrongs and to fully restore the moral situation for the victim such that it would be as if the original harm had never occurred. Feinberg, for instance, writes that compensation "functions not only to repair the damages but also to 'restore the moral equilibrium,' as would an apology or expression of remorse" (Feinberg, 1970a, p.74). The strong compensation claim is perhaps expressed most clearly by Goodin: "From a moral point of view, the function of compensation is straightforward. Compensation serves to right what would otherwise count as wrongful injuries to persons or their property" (Goodin, 1991, p.257). Contrast this with the weak compensation claim: that, given a previous wrong, compensation can repair the harm but not fully restore the moral balance. Gaus (1991), for example, argues that compensation can only restore moral imbalances in those cases where the right's infringement was justified in the first place. The standard view of the repairing qualities of compensation is much closer to the weak claim than to the strong claim. It is often argued that compensation cannot address moral wrongs at all, but merely losses; or that compensation, though it contributes to righting wrongs, does so to a lesser degree than apologies or punishments do. Roberts (2002), for example, suggests that compensation must be accompanied by an apology in order to right a wrong. Griseri (1985, p.402) suggests that compensation is often demanded in lieu of complete annulment, that is, when things cannot be made fully right.

What would be required of an act of compensation in order for it to fully rectify a wrong? There are three distinct positions about what it would require to morally repair a wrong via compensation: 1) Moral reparation requires only reparation of harm (the wrong consists in nothing but the harm); 2) Moral reparation requires reparation of wrong (where the wrong is distinct from the harm); 3) Moral reparation requires reparation of both harm and wrong (where these are distinct). I shall argue position 2 is the most reasonable one. Position 1 rests on the assumption that the wrong of an action consists in nothing but the harm. This seems reasonable enough as a utilitarian assumption but seems 
insufficient on any non-consequentialist account. Position 3 might seem preferable to 2 in that it covers both harm and wrong. However, in many cases the reparation of harm may not be possible or necessary in order to right the wrong. The position argued for in this paper is that full repair requires compensation such that the right kind of meaning of repair and regret is conveyed. I will argue that, if we assume an expressive interpretation of moral wrongdoings and formulate an equivalent expressive conception of compensation, then there is a case for the strong compensation claim. When compensation fails to be expressive in the right way, compensation cannot fully repair moral damage on its own.

In this paper, I focus on three clusters of problems divided over five sections. The first problem (sections 1-2) consists in finding a plausible account of compensation that could explain how wrongs could be righted. The second problem (section 3) is to work out the finer details of apologetic compensation: what makes a particular act of compensation successful in communicating regret and re-writing the message of the wrongful act? The third problem (sections 4-5) takes us back to the main question: is apologetic compensation sufficient to right a wrong, and can the strong compensation claim be defended? In the last section (5) I briefly apply this to the moral problem of risk impositions.

\subsection{The Indifference Criterion.}

Is there an account of compensation that could make the strong compensation claim convincing? According to Nozick, full compensation is provided when the victim is on the same indifference curve as they were before the harm occurred.

Something fully compensates a person for a loss if and only if it makes him no worse off than he otherwise would have been; it compensates person $\mathrm{X}$ for person Y's action A if X is no worse off receiving it, $\mathrm{Y}$ having done $\mathrm{A}$, than $\mathrm{X}$ would have been without receiving it if Y had not done A. (Nozick, 2006, p.57)

This means that I could be compensated in a number of ways, as long as I am indifferent between being harmed but compensated and not being harmed. Compensation is achieved by making the victim "as well off" as they would have 
been had the original incident not occurred. The basic idea of the indifference criterion seems to appeal to one of two rather different intuitions and lines of reasoning. Let us refer to them as the "no worse off" and the "would not mind" readings of the indifference criterion.

\section{1. "No Worse Off."}

The "no worse off" reading says little more than that full compensation requires that the person harmed ought to be compensated in such a way that they are "no worse off" than if they had not been harmed. This accords with Goodin's account. For him, to compensate someone is to provide "a full and perfect equivalent" for what was lost or harmed (Goodin, 1991, p.262). Essentially, the loss of a means to a valued end is compensated for when some equally good means to the same end is offered. When such an equivalence is not possible, full compensation would require providing means to a different end that still makes the person as well off as they would otherwise have been. The point is that it is the fact that an act of compensation makes the victim as well off that gives it its reparative properties. Goodin's account of compensation is, thus, one of a return to the previous status quo ante, a return, as far as possible, to the way things were before the loss or damage, either by offering similar means to the same end or by offering means to a different but equally valuable end (see, e.g., Chapman, 1995, p.409). Central to this account is the proportionality between loss and compensation (see, e.g., Corlett, 2002, p.148). A is a perfect equivalent for B if A is neither more nor less than $\mathrm{B}$ and if $\mathrm{A}$ restores the compensated person to the same baseline of wellbeing as before the original loss of A.

To compensate someone for something is...to provide that person with 'a full and perfect equivalent for that thing'. If he is given more than that, we would say that he has been 'over-compensated'; if less, 'under-compensated'. Being bracketed as it is in between these other two notions, the notion of compensation per se clearly implies the providing of the exact equivalent - neither more nor less. (Goodin, 1991, p.262)

Could the "no worse off" version of full compensation make a convincing reading of the strong compensation claim? The idea that compensation can right 
a wrong by making the victim "no worse off" only makes sense if the person suffered a loss in wellbeing (on some measure) as a result of the wronging act and that they would have been better off in terms of wellbeing had they not been so wronged. A wronging act need not, however, lead to a loss in wellbeing. It could be a case of "harmless wrongdoing" (Ripstein, 2006). Such cases of wrong could not be repaired morally via compensation since there was no loss in wellbeing to compensate for. More worrying are cases of wrongful harms that seriously harm the victim but that also lead to an increase in wellbeing overall (for the victim). In such cases, where the harmed and wronged person is made as well off, or better off, by the resulting set of events, it would not be possible to right the wrong by making the person "as well off". The problem stems from the fact that wellbeing, as a measure, tends to be aggregative when applied to one and the same person. Furthermore, serious rights violations (that do not leave the person as well off) could be made right by simply making that person better off (in some respect). Such cases would allow for exploitations of those who are already vulnerable. If someone lacks basic needs, then providing those needs seems to make the person better off even if they are exploited. We do not want to say that if the victim is poor enough then one can do whatever one wants to them as long as their education is paid for, food is bought, shelter is provided, etc. To sum up, the "no worse off" version of successful compensation rests on the assumption that a wrong is put right because the resulting loss is repaid. But this leaves the moral wrong, over and above the harm done, basically unaddressed.

However, this objection only holds if we read the indifference criterion as a return to status quo criterion and view wellbeing as an aggregative measure. Although Goodin does suggest "a return to the same baseline of wellbeing" as a criterion, that is primarily in the context of valued ends, and he favours compensation in the form of replacing means lost with some perfect equivalent means to the same end. Furthermore, he does not argue that compensation is sufficient to right wrongs in all cases. Nonetheless, the "no worse off" criterion seems to only support the strong compensation claim if we assume the first position mentioned in the introduction: that it is sufficient to only repair the damages in order to right the wrong. Nozick partly avoids this worry by making indifference the righting criterion since a person in such a case would not be 
indifferent between being wronged and not being wronged. This brings us to the "would not mind" version of full compensation.

\section{2. "Would Not Mind."}

In the second reading of the indifference criterion, preferences seem to provide something of an equivalent to consent, expressing the will of the person subjected to the harm or loss. The argument goes something like this:

1. Person $\mathrm{X}$ is indifferent between $\mathrm{i}$ ) no harm and ii) harm and compensation.

2. If person $X$ is indifferent between $\mathrm{i}$ ) no harm and ii) harm and compensation, then person $\mathrm{X}$ does not mind ii) harm and compensation.

3. From (1) and (2): Person X does not mind ii).

4. If person $X$ does not mind ii), then ii) is permissible.

5. It is permissible for $\mathrm{Y}$ to harm $\mathrm{X}$ if $\mathrm{Y}$ fully compensates $\mathrm{X}$ (i.e., option ii).

The initial problem is how to make sense of premise 1 . What does it mean to say that X is indifferent between "no harm" and "harm and compensation"? Nozick admits: "Shamelessly, I ignore general problems about the counterfactual 'as well off (on as high an indifference curve) as X would have been if Y's action hadn't occurred”' (Nozick, 2006, p.57).

The most problematic step in the above argument is the one from "would not mind" to moral permissibility (that is, premise 4). What is it in "X would not mind being harmed and compensated" that could make harmful action morally permissible? I think we have a general tendency to think that if $\mathrm{X}$ "would not mind" then they would also consent to it (if asked). This seems to be what it means in everyday language. When leaving the house in the pouring rain, we might take our partner's umbrella knowing that they "would not mind". The reason for this, perhaps, is that we know that they have no issues about lending things or have done so willingly in the past.

On what grounds can Y presume that X would consent to be harmed if compensated? First, we can look at it "materialistically", as in the "no worse off" argument. If the situation is objectively as good as before, then they have no reason not to consent to it. Consent is then presumed by some reference to what 
is rational for $\mathrm{X}$ to consent to in an impersonal way, which might miss quite a few aspects that $\mathrm{X}$ takes into account but $\mathrm{Y}$ does not. Secondly, we can consider the actual preferences of $\mathrm{X}$ and conclude that, given those preferences, they ought to consent to A because they would prefer $A$. Thirdly, we can consider the preferences of a larger group, and, presuming that X's preferences are the same as those of that group, conclude that, given the preferences of that group, they are likely to consent to $A$. I will address the first two in turn. The third will not be addressed separately since it is merely a weaker form of the second option.

What about the first idea that, given that the person is "no worse off", they have no reason not to consent? This idea relies on an objective comparison of states of affairs and a judgment that they are equally good for $\mathrm{X}$. The assumption is that if they are equally good then there is no reason to prefer one to the other. This might be right if the two states were precisely equally good on all relevant measures. However, usually such claims are based on more narrow measures that take some aspects into account and not others (as in the case of cost-benefit analysis, for example). If so, then there could always be extra reasons to prefer one to the other. Even between two states that are equally good in all respects, if one is current and the other is not, this could provide grounds to prefer one to the other, depending on whether the person prefers change or actual values. Thus, if we assume status quo bias (Samuelsson and Zeckhauser, 1988) or a conservative preference of existing value (Cohen, 2012), the victim could have reasons not to be indifferent between two otherwise equal states. (Furthermore, if harm and compensation were to improve the situation for the victim compared to not having been harmed at all, this would-besides being a case of "over compensation"-open up to the same kind of concerns about exploitation that I raised against the "no worse" off reading.)

I shall argue that, even if we had perfect knowledge about the preferences of $\mathrm{X}$, this would not constitute sufficient grounds for inferring their consent. There are several problems with the "would not mind" argument if understood as inferred consent from preferences. First, consent is a form of permission given before the violation has occurred. But if what makes the violation permissible is an indifference between compensated harm and no harm, it is hard to see how there could be an indifference between the two that the violator could know of 
before the harm (and compensation) has occurred. My point is that "indifference" is a particularly tricky sort of preference to infer because it is a comparative judgement over two states that cannot both be instantiated at the same time.

Secondly, preferences might be very weak and reflect an almost arbitrary preference in any given moment, or else they might have been swayed and influenced by biased and/or insufficient information. Suppose that a voter can choose between two candidates, P and Q. However, at a particular point in time, she has only informed herself about the policies of candidate $\mathrm{P}$ and not yet those of Q. Being swayed by P's policies, she might at that point in time prefer P. This does not make it right for us to take away her right to vote and, on the grounds of her preference for $\mathrm{P}$ over $\mathrm{Q}$, infer her consent to $\mathrm{P}$. The problem, as I see it, is that inferred consent robs the agents of the choice to decide when they are sufficiently informed to consent and when to postpone a decision. Presumed consent has replaced consent proper. ${ }^{1}$

The indifference criterion is helpful in that it takes into greater account the victim and their subjective experience of harm and compensation. But much of that is greatly weakened if the person is not consulted at all, and her preferences are inferred from an average understanding of which preferences she rationally ought to have or which preferences she is most likely to have from a sociological point of view, when in fact none of these might reflect their actual preferences. It seems, then, that compensation, if based on a hypothetical indifference, gives too much liberty to the violator to both harm the victim and to determine when they think this violation has been compensated for.

\subsection{Harms and wrongs.}

There are two related objections that could be raised against both versions of the indifference account. The first objection is that although the harm might be repaired, the wrong is ignored. This objection presumes a distinction between

\footnotetext{
${ }^{1}$ Railton makes a similar point against Nozick's idea of compensation as a way to legitimise risk impositions without consent. Railton writes about the victim saying that there is a "preemption of his actual will and of his sovereignty, his entitlement to decide certain matters himself." See Railton (1985, p.115). The point I am making above is that this same objection can also apply to cases where the preferences at a particular time are known.
} 
the harm² of a rights violation (the loss of a piece of stolen property, the bruises from a physical attack, etc.) and the wrong of a rights violation (the violation of the right not to be stolen from, harmed, etc.). Olsson steals Anderson's bicycle. In doing so, he does two things to Anderson: he causes a loss of his bicycle, and he wrongs him in violating his right to his bike. The loss could have occurred in other ways than through a crime. Replacing the bicycle with a new one would replace the loss, but not the theft. This view of compensation treats thefts no differently from losses, and, therefore, cannot claim to be a theory of moral compensation.

The second objection is related to the first. If it is sufficient to compensate another in contexts of indifference, then the very same wronging act could be repeated as long as it is compensated for. The wrongdoer might keep violating the rights of another but be ready to compensate for the act each time. Moral impermissibility is basically reduced to a transaction cost. Or, as Railton puts it in his critique of Nozick's idea of compensation as legitimising risk impositions: "compensation is nothing but a price attached to the pursuit of one's own ends" (Railton, 1985, p.115). We could imagine a bully that routinely violates the rights of another but also fully compensates them each time. In such a case, these exchanges of compensations seem less to communicate a wish to restore violated rights than an acceptance of a price for violating them and a lack of respect for them.

It might be the case that the "would not mind" version fares slightly better against this objection. It could perhaps be argued that a particular individual's indifference would eventually wear off; that, after a number of compensated trespasses, indifference could no longer be achieved and such trespasses would need to stop. However, it could just as well be argued the other way around. Radzik (2004, p.147), for example, suggests that being wronged can cause the victim to doubt their value. If a victim can come to doubt their own value, then they might not be in a position to decide when compensation is sufficient. This is particularly worrying if the harm is repeated (even if compensated for). They might, as a result, lower their expectations of compensation and thereby lower

\footnotetext{
2 "Material harm" is here intended to make it clear that I have negative physical changes in mind. I am referring to damages, injuries, losses, and the like, and not to more abstract ideas of harm such as "set-back to interests" or the like.
} 
the "cost" of harming them. In other words, there is a risk that they might "not mind" a lower and lower level of compensation.

\section{The negation criterion.}

The main problem with the above accounts is that they fail to deal with the wrongfulness of the previous action. This is a general complaint often directed against compensation as a means to make amends (see, e.g., Marshall, 2001; Roberts, 2002). The question is whether accounts such as those discussed above exhaust the possibilities. According to the strong compensation claim, compensation can put right what would otherwise be held as a wrongful act. But restoring the damage done, or returning the victim to the same level of wellbeing as before, or even making them indifferent to the harm done, is insufficient to achieve this. If the strong compensation claim holds, then we need to say something rather Hegelian in nature: that the wrongful act can be annulled or negated in a way that not only restores the material harm but also restores the rights of the victims. This point has, however, mostly been addressed with regards to theories of punishment and not of compensation (see, e.g., Griseri, 1985). I will refer to this idea as the negation criterion of compensation: compensation rights a wrong when it negates that wrong.

\subsection{Actions as Expressive of Meaning.}

The negation criterion presumes that actions convey meaning, and Hampton suggests that all actions carry conventionally understood meanings that are accessible to all (Hampton, 2007, pp.118-120; see also Murphy, 1988, p.25). Following this idea, we have a different analysis of wrongdoing: the problem lies in what is expressed in the wrongful act. According to Hampton: "It is because behavior can carry meaning with regard to human value that it can be wrongful" (Hampton, 2007, p.119). Hegel expressed a similar thought: "His [the criminal's] action is the action of a rational being and this implies that it is something universal and that by doing it the criminal has laid down a law which he has explicitly recognized in his action...” (Hegel, 1973, p.70, §100). In contrast to the accounts discussed above, the violation of rights of another does not consist in merely harming another but also in making a statement about the permissibility to do so. It is this message that is negated by the state in doling out punishment according to expressive theories about punishment. In Hampton's 
version, the criminal makes out that they have greater moral worth than they, in fact, do, and that the victim has lower moral worth than they, in fact, have.

A person behaves wrongfully in a way that effects a moral injury to another when she treats that person in a way that is precluded by that person's value, and/or by representing him as worth far less that his actual value; or, in other words, when the meaning of her action is such that she diminishes him, and by doing so, represents herself as elevated with respect to him, thereby according herself a value that she does not have. (Hampton, 2007, p.126)

A similar testimonial idea is expressed by Radzik:

The wrongful act functions as a kind of testimony that this sort of treatment of the victim is acceptable. If the victim believes the testimony, if any spectators to the wrong believe it, or if the wrongdoer himself is encouraged by the apparent acceptance of his claim to superiority, then further wrongs and further harms become more likely. (Radzik, 2004, p.142)

Given this view, we can treat wrongful harms as actions that, on the one hand, cause injury or loss, and on the other, express a disregard for the rights of the other. Compensation must then seek to both cover the losses and negate what was expressed in order to annul the harm.

There is, however, an additional complication that follows from an expressive analysis of wrongdoing: the impact of such messages. In the quotation above, Radzik mentions that this message could affect the victim, spectators, and the wrongdoer himself and have effects that last long after the original harm. We have already mentioned in section 1.3 the possibility of rights violations affecting the self-esteem of the victim and that repeated harms might cause the victim to doubt their own worth and moral status. To this we can add the fear of being treated the same way in the future. The threat from the criminal is still there if the violator still condones his crime. Radzik again: "To wrong another person is to insult and threaten him. To do nothing (or fail to do enough) to correct that action is to allow the insult and the threat to stand" (Radzik, 2004, p.142). The wrongdoer might even take the lack of protest as an expression of support and make them respect such rights even less in the future. Then there is the impact on spectators who might be influenced by the criminal and take the victim's rights less seriously. They might become more passive in the future when others are treated in similar ways. There are thus three dimensions to wrongful harms and to moral rectification: direct harm done to the victim (self-worth, fear and risk of future harms, and actual harm); effects on the wider moral community (respect for rights of others generally and respect for the rights of the victim in particular); 
and the conscience and will of the violator (condoning or opposing his criminal act).

\subsection{Restating what is right.}

In the retributivist version, what needs to be done in order to reinstate the status of rights is to punish the criminal. And this punishment must presumably be such that it communicates to the criminal, to the victim, and to the wider community, that what has been expressed in the criminal act does not hold. Outside the criminal context, what is required is often some kind of apology. Compensation seems to fall somewhere between punishment and the informal repair of apologies.

According to Hegel, the will of the violator is not only the cause of the violation of the right but also where the wrong "resides", and thus it is the necessary object for punishment in order to achieve a negation of the crime (see Brown, 2001, for discussion).

The sole positive existence which the injury possesses is that it is the particular will of the criminal. Hence to injure [or penalize] this particular will as a will determinately existent is to annul the crime, which otherwise would have been held valid, and to restore the right. (Hegel, 1973: 69, §99)

For Hegel, punishment is meant to annul the crime insofar as the locus of the crime lies in the will of the criminal (Hegel, 1973, pp.69-70, §§98, 99). Punishment thus denies what was expressed in the wrongful action and reestablishes what is right. Similar thoughts run through later expressive theories of punishment (see, e.g., Feinberg, 1970b; Duff, 2001, esp. 27ff): what is right is communicated to the criminal through an act of punishment to "reconnect him with correct values" (Nozick, 1981, 374ff) or to make him comply with the values of the community (Duff, 2001).

Where does this bring us with regard to compensation and the claim that compensation can right wrongs? Just as punishment is an action with a different message than the criminal act, so too can compensation offer a different message than the original wrongdoing. But there is an interesting difference. Punishment can communicate to the community and to the criminal the values of the state. It can defend the rights of the victim and communicate such rights to the community, to the criminal, and to the victim. But punishment is imposed on the 
wrongdoer externally. Compensation, by contrast, can be offered by the wrongdoer himself. It can, of course, be something externally required of the wrongdoer. But it need not be. And even when forced, it can be offered out of genuine contrition. In short, compensation can communicate a change of heart where the wrongdoer now supports the rights of the victim. As an example, we can think of compensation to victims of earlier government policies that violated the rights of less protected groups in the past. The mere act of compensation signals a change of values: we no longer condone forced sterilisations, we ought not to have let insufficiently tested medical drugs be prescribed to pregnant women, etc. However, in such cases it would often be a later government rather than the original one that committed the violation.

We may now begin to address one of the objections to the strong compensation claim. The claim that compensation can only restore the harm done and not the wrong seems to overlook the expressive capacity of actions. If criminal acts and punishing acts can communicate then presumably so can compensatory acts. If an act of compensation could address both material harm and the moral message then we would have something approaching a supportive case for the strong claim of compensation.

\section{3.o Apologetic and non-apologetic compensation.}

The preceding discussion raises a distinction between what we might refer to as apologetic compensation and non-apologetic compensation. To compensate someone non-apologetically is to offer money, goods, or services to repair damages or losses incurred by a previous act but not to admit to any wrong or to express any regret. It is often pointed out that this kind of compensation is insufficient to make amends for wrongful harms. Marshall (2001), Roberts (2002), and Lazar (2008) argue that compensation is insufficient and needs to be accompanied by an apology. Smith (2008) takes an even more pessimistic view of compensation. In a discussion of what he refers to as "compensatory apologies", he claims that even when compensation is accompanied by an apology, such an apology "accepts no causal responsibility, admits no wrongdoing, and expresses no opinion of the underlying value." He continues: “Apologetic language may accompany such exchanges [of goods to the injured 
party], but will typically commit to little more than expressing sympathy" (Smith, 2008, p.149).

In contrast, I would like to introduce the idea of a genuine apologetic type of compensation. Apologetic compensation is compensation offered by the wrongdoer as a gesture expressing regret or remorse over the harming act and a desire to put things right. The regret and the wish to put things right are the very reasons for compensation. But rather than expressing this in a verbal apology, this remorse is expressed in the compensatory offering of goods, money, or services. It is acknowledging wrongdoing and expressing regret over and above any physical damages or losses.

To illustrate the difference between the two, we can compare the following two examples. First, take the case of the Bullingdon Club, the infamous Cambridge dining club known to select restaurants to vandalise after the club's annual dinners (Ronay, 2008). The club members supposedly offered very generous payments to cover all such damages after having trashed their eating venue. Considering that this practice was repeated over many years, the compensation cannot be said to express genuine remorse. This would be a case of non-apologetic compensation. (This would be so even if the compensatory act was accompanied with some verbal apology.) Compare this to a case where a child has accidentally broken an antique gramophone that they knew they should not have played with and offers their entire collection of seashells to the owner to make up for it. In such a case, the damages are far from repaired. However, we could easily accept the gesture as one expressive of regret, of responsibility for the harm caused, and of a genuine wish to never have done it in the first place. This would be a case of apologetic compensation.

To the extent that the above examples have any intuitive support, they imply the following: 1) that there is a case for restorative apologetic compensation, that is, a case for compensation that repairs by expressing apology rather than by restoring loss; and 2) that full material compensation can be morally unsatisfactory when unapologetic. None of this should be all that controversial: in the private sphere of morality we offer flowers to make up for minor harms, as consumers we are often generously reimbursed for faulty products or mistakes, etc., and there is often a demand for apology when compensation is offered, as in 
cases where wrongs toward certain groups in society have been committed by policies enacted in the past. Typically 2) would be taken to suggest a need for compensation plus apology. What I am claiming here is that there is an alternative to compensation-plus-apology that follows from the expressive potential of compensation: apologetic compensation. That a verbal apology can communicate an apologetic message is obvious. Here the claim is that compensation can be apologetic.

At this point, it might be objected that it is far from obvious that there is any important difference between apologetic compensation and compensation-plusapology. If not, the defence for the strong compensation claim would fail, since compensation could not suffice to repair wrongs unless also accompanied by an apology either in the same act or as a separate act. We will return to this objection (section 4.1), but in order to respond to it we need to say something more about what a sincere and complete apology requires (section 3.1), how an act of compensation could be apologetic in that sense (section 3.1), and what the possible criteria for righting wrongs by means of compensation would require (section 4). I hope that, once we fit all these pieces together, the position that apologetic compensation amounts to something more and other than compensation-plus-apology becomes clearer. I also hope to clarify how apologetic compensation can repair moral wrongs qua compensation.

\subsection{Meaning of apologies: regret and acknowledgement.}

We will now need to say something about how an act of compensation could express an apology. It might be illuminating to say a few things about apologies in general. Smith (2008, p.80), for example, refers to the promise never to repeat the offense as one of the most important aspects of an apology. 3 This is of interest

\footnotetext{
${ }^{3}$ Smith's (2008) account of "categorical apology" offers too thick a notion of apology to be of much help in illuminating the idea of apologetic compensation. He argues that categorical compensation, among many other things, requires both parties to acknowledge the same underlying values, the norms transgressed, and a shared narrative over the event. This seems to be too demanding for a general account of apologies. In most cases, it seems to suffice to acknowledge the reasonableness and entitlements of the other person's perspective without sharing it. It must be possible to be apologetic across cultural barriers, across ethical barriers, and across language barriers. One of the beauties of apologetic compensation is that it can be expressed, and recognised as apologetic, over such barriers. I can realise that I have insulted someone by overstepping cultural norms, such as showing the soles of my feet to someone, and duly apologize for the insult and wish I had not done it without sharing those norms or the narrative. Out of Smith's listed twelve criteria for categorical apology, several $(1,4-7)$ to some degree implicitly presume a common spoken language and apology as a discursive practice. See Smith $(2008,140-142)$ for a summary of all twelve points.
} 
to us because one of the major objections to compensation as a way to make wrongs right was, as we saw earlier in the discussion about Nozick and Goodin, that it does not express any intention to refrain from similar acts in the future. The notion of apologetic compensation challenges this objection and rests on the assumption that, in a compensatory act, it is possible to demonstrate a will not to repeat the same offense.

The second aspect of an apology stressed in the literature is acknowledgement, in particular acknowledgement of responsibility and of some kind of culpability (see, e.g., Gill, 2000; Govier and Verwoerd, 2002). Gill (2000) lists the following five aspects of an apology:

1. An acknowledgment that the incident did in fact occur;

2. An acknowledgment that the incident was inappropriate in some way;

3. An acknowledgment of responsibility for the act;

4. The expression of an attitude of regret and a feeling of remorse; and

5. The expression of an intention to refrain from similar acts in the future. (Gill, 2000, p.12)

A good place to start would be to assume something like the following: to the extent that an act of compensation can convey aspects 1 through 5 above, it is an apologetic act of compensation. Interestingly enough, it seems that all of these aspects can apply, to a greater or lesser extent, to compensation. Even a nonapologetic act of compensation necessarily admits to some kind of responsibility for what happened and that it did happen (1 and 3), or else there would be nothing to compensate for. What non-apologetic compensation fails to communicate is an intention to act differently in the future, acknowledgement of culpability, and remorse (2, 4, and 5). Apologetic compensation should communicate all five (with the possible exception of 3 in cases where we compensate on someone else's behalf, such as when one government apologises on behalf of an earlier one). This seems intuitively right, but on what grounds would we say this?

As a starting point, I will propose three different aspects that could be expected to affect the apologetic impact of compensation either jointly or independently: a) the value or generosity of what is offered; b) the degree of 
sacrifice or effort involved; and c) the degree of sympathy and understanding for the nature of the harm as perceived by the victim. There might well be other aspects, but I will focus on these three.

a) Value or Generosity. In monetary terms, the Bullingdon compensation was more generous than the seashell offer. Furthermore, the Bullingdon compensation probably covered all the actual costs of the damages, and possibly more. Yet it does not convey nearly as much of an apologetic message as the child's gesture. It could be argued that the child's offer was, in fact, more generous in that it represented a much larger proportion of all their valued possessions. One could argue that, by a gesture of compensation, the wrongdoer is putting a fictive price on a moral trespass. If this is set too low, relative to the wrongdoer's total wealth, then he has basically given himself an allowance to repeat the same harm as long as he compensates what he himself has decided is due. Thus, it is only when what is offered is so expensive to him that he cannot afford to pay it again that true regret is expressed. The child, according to this idea, would, when offering their only seashell collection, set a price on their trespass that they would never be able to pay again and thereby be taken to be expressing a genuine regret.

This might be successful in communicating the message in one-off cases in the interpersonal case, but when it comes to a government or a large enterprise that might wrong others more than once, or more than one person, this way of expressing regret becomes impractical. A government might well offer such generous compensation as to never be able to make the same mistake again and still be able to compensate for it. The very idea of "total wealth" when applied to governments with debts and an income based partly on taxing its citizens is problematic in itself. This approach becomes even more problematic if we assume that any solutions for preventing similar problems in the future must be financed from the same source that compensation would be due from (i.e., the taxpayers).

But perhaps the idea could be much simpler: an act of compensation can convey regret if perceived as generous by the victim (for whatever reason). In this way, we could leave it open whether the generosity is to be understood in monetary terms, or symbolically, or relative to the wealth of the compensator, or 
relative to the wealth of the compensated. This is too vague to be of much guidance, but it is not obviously false.

b) Sacrifice or Effort. An alternative solution would be to sidestep the idea of value and go straight to the cost in a more general sense, including costs in terms of time and effort. A common objection against compensation is that the wrongdoer might insure herself against it and be let off too easily (Marshall, 2001). This could be interpreted as wrongs being permitted at too low a cost. But it could also be read in a different way: that compensation is emotionally or morally too cheap. If harm has already been insured against, then there is no extra cost involved in harming another, and the violator could remain detached from the results of his or her actions. In contrast, it could be argued that compensation can express apology when it involves some form of penance or sacrifice. Radzik suggests something along those lines: "A self-imposed punishment can contribute to reconciliation by serving as a further sign to the victim and the community that the wrong-doer takes his error seriously and is trying to recommit himself to a moral life" (Radzik, 2004, 149). She writes:

Giving a gift to the person one has wronged can be a form of penance, especially if the gift requires a significant amount of effort or sacrifice from the wrongdoer. In other cases, the wrongdoers perform some service for the person they have wronged as a mode of penance (for example, after a quarrel with his mother a son may dedicate his weekend to cleaning her garage). (Radzik, 2004, 144)

However, suffering by itself does not necessarily make an act of compensation more apologetic. Adding a good portion of flagellation would not necessarily make monetary compensation more successful in righting a wrong. This could instead be perceived as something rather self-centred and morally demonstrative, directing attention away from the actual victim to the wrongdoer. On the other hand, there seems to be something morally disturbing about first committing a wrong and then helping oneself to great privileges. Thus refraining from gains one would otherwise have enjoyed might have something to do with sincere regret. (This seems particularly important in cases where there might be a link between gains for the rights violator and the harm done to the victim.) 
Putting more rather than less effort into the repair could make the act more apologetic. Replacing the loss with money or what is close at hand is less convincing as an act of apology than going to the trouble to find something that is more significant to the victim, to find the "perfect thing" to heal the harm done.

c) Sympathy or Understanding of Harm. The third option for conveying apology through compensation is to compensate in a way that demonstrates sympathy for the victim (Feinberg, 1970a, p.76). This would solve the problem of compensation being emotionally too cheap and yet avoid the charge of being too focused on the violator. The act of compensation would, according to this idea, express sympathy with the losses or injuries as the victim perceived them and try to repair these harms. This plays into the acknowledgement part of apologetic meaning: to acknowledge what happened to the victim as a result of the decisions or actions of the wrongdoer. 4 The problem with monetary compensation is that in many cases it can be handed over without any such acknowledgement, especially if it has been insured for before the harm has occurred (Marshall, 2001). Money might be essential to repair what was done, but then the acknowledgement part could still be wanting. Perhaps this is the reason for the common requirement for an apology and compensation. But compensation can also be sensitive to the harm as perceived by the victim. In particular, replacement in kind leaves a lot of room for sensitivity to subjective harm. In many cases, things lost or broken carry more than one kind of value. Perhaps the broken thing reminds the victim of the place where he proposed to his wife. If such losses are to be compensated for, then it would seem that, even if all values lost cannot be replaced, they can all be acknowledged. If the place where the victim proposed no longer exists, perhaps some other memory from the wedding can be found. Even if the compensator were to be unsuccessful in trying to find the "perfect thing", merely having put the thought and effort into it would convey an acknowledgement of the values that have been lost.

\section{Can Apologetic Compensation Right Wrongs?}

\footnotetext{
${ }^{4}$ Smith (2008) goes further: a genuine apology requires the violator and victim to share the same description of what happened. But this seems too strong. We can sincerely apologise for wrongs we commit against a value standard that is not our own. Perhaps the most common example would be overstepping the norms of a different culture and unintentionally insulting someone.
} 
This paper began with what I referred to as the strong compensation claim: that full compensation is sufficient to right wrongs and to fully restore the moral situation for the victim such that it would be as if the original harm had never occurred. The most obvious problem for the traditional understanding of compensation is that compensation seems to only repair the material harm but not the moral aspects of the harm. This has commonly led to the idea that compensation is morally incomplete and needs to be supplemented with an apology. I have argued that compensation can, in fact, be apologetic and, in that way, also repair the wrong.

What are these moral aspects of harm? We borrowed Hampton's idea from the retributivist justice literature that in some (criminal) acts the wrong consists of a message about the moral value or worth of the other. Or, to put it in Hegel's cruder terms, the criminal or wrongdoer "lays down a law" in their act by suggesting a more permanent impact and influence on others. What follows from this is that in order for such a wrong to be rectified we have four aspects to take into account: 1) the message itself as an expression of the values or intentions of the criminal; 2) the moral impact of the message for the victim; 3) the moral impact of the message on the wider community; and 4) any material consequences of the act itself apart from the impact of its message. The first three would then constitute the wrong, and the fourth aspect would constitute the harm.

To what extent does an apologetic act of compensation need to remove the impact of the original message, and to what extent does it need also to repair the material harm brought about by the wronging? Compare these three positions:

The Full Compensation Hypothesis: an act of compensation (provided by the wrongdoer to the victim for a previous wrongful act) can right a wrong if the previous wrongdoer compensates for all damages and fully apologizes for the whole of the wronging act.

The Forgiveness Hypothesis: an act of compensation (provided by the wrongdoer to the victim for a previous wrongful act) can right a wrong if the compensatory act suffices to make the victim fully forgive the wrongdoer. 
The Expressive Compensation Hypothesis: an act of compensation (provided by the wrongdoer to the victim for a previous wrongful act) can right a wrong if the message expressed by the compensatory act fully overwrites the message expressed by the wronging act.

The underlying idea of compensation is one of replacement, or, rather, repair by replacement. It would then seem reasonable to assume that, whatever negative impact a particular act had, that impact must be "replaced" or removed in order to right the wrong. Yet the full compensation hypothesis is too demanding. It would require not only full moral repair but also that all material loss was fully replaced-with all the problems that follow. In many cases, this cannot be achieved. (There is also the additional worry over the need for double compensation: one for loss and one for wrong). For something like the full compensation hypothesis to hold, we need a weaker criterion for success than full repair of all harm. One way to do this would be to lessen the requirements for full compensation to a requirement to try to compensate as fully as possible. We could require that the compensator acknowledge all aspects of the harm and wrong committed and try as far as possible to rectify all aspects of those harms and wrongs. In such a case, it would be the trying that would right the wrong. This approach would still leave the question open as to when an attempt to rectify the impacts is sufficient to right the wrong.

Alternatively, we could start with forgiveness and argue that a wrong has been righted when forgiven by the victim. Such an account would provide a precise criterion for when a wrong has been righted, whether compensated for in full or apologetically expressed in compensation. But forgiveness does not seem to be the criterion we are looking for either. First of all, the victim might not be able to forgive the violator no matter how apologetic the compensator is or how thoughtful and generous the compensatory act. Secondly, it would render all cases where the victim did not think herself wronged, or did not know herself to be wronged, problematic. Thirdly, the most serious worry about the forgiveness criterion is that there might be a complete mismatch between when a person actually forgives another and our moral intuitions about when they ought to do so. One person might simply never forgive another even for the slightest mistake, or else they might exploit the opportunity to demand unreasonably high 
compensation. Another person might easily forgive even the gravest wrongs without the wrongdoer offering much by way of either compensation or apology.

Instead, I think we need something more inter-subjectively accessible, something like a concept of "forgiveness-worthy" akin to "trustworthy". I suggest that we assess compensation with the same criterion with which we assessed the wrong: in the message expressed. Does an act of compensation roughly convey an apologetic message equivalent to Gill's list? Or is it a clear expression of respect for the moral rights of the other with an acknowledgement that a moral boundary was violated in the wronging act and that this boundary will be respected in the future? Is such a message one that could be understood by all that could see the wrong in the previous act? If so, then we have an act of apologetic compensation that could be recognised as "forgiveness-worthy". Presumably, some acts of compensation will appear to us as expressive of genuine regret, a genuine will to make things right, a genuine acknowledgement of the rights of the other, of the wrong done, etc. I think we could reasonably claim that those acts also succeed in righting wrongs. Perhaps to make it more precise we could say something like this: an apologetic act of compensation rights a wrong when a sufficiently informed person (that is, one knowing about the wronging act and the compensatory act) would recognise it as a genuine act of repair that seems apologetic enough to be worthy of forgiveness by the wronged party.

What then would such an act require? Essentially, compensation is about either a) making it as good as it was or b) making it as good as it ought to have been. We have mostly been occupied with the first part: making it as good as it was. This idea is rather straightforward when it comes to losses or injuries. I replace like with like when possible but in a way that is more generous: I put in more effort to make it right, and I am very sympathetic in understanding which values were, in fact, at stake. The object that was lost might mean very different things to different individuals. A broken cup might not just be a cup but also the only memory of a beloved grandfather. A random new cup would only replace one value. But, should the compensator find a rare cup precisely to the victim's taste and seek high and low for some other memory from this grandfather to bring back, then these two acts would jointly provide a "forgiveness-worthy" case of compensation. 
I now want to say something about "a return to how things ought to have been”. This applies in particular when policies or cultures have committed systematic wrongdoings against a particular group in society. Take cases like forced sterilisations, slavery, and all kinds of hospitalisations or medical interventions that are not medically motivated. Compensation for such instances of wrongs cannot make things right by offering a return to how things were before a particular act if those acts were not a deviation from the norm at the time. Here we must draw another distinction between historic cases and current cases of systematic rights violations and rights denials. These cases must be treated differently. In demands for compensation for historic cases of wrong, part of the moral work of repair has often already begun in the form of changes of policy, values, and legal rights. There might be no need for an act of compensation to express "an intention to refrain from similar acts in the future" because the enabling values have already changed. The demands for compensation must instead be understood as compensation in the form of acknowledgement of previous wrongs, acknowledgement of equal rights, and acknowledgement of the lingering impact such previous wrongs might have had and continue to have. One such lingering impact might, for example, be the "invisibility" of a certain group. Such "invisibility" could be compensated for by greater representation, greater inclusion in history curricula, in honorary gestures like the naming of important institutions, events, and places, etc.

When it comes to compensation for wrongs that express the existing culture of values, we might have come to the far limit of the strong compensation claim. We might even state the following hypothesis: only when a moral right is publicly acknowledged in society, whether formally or informally, can an act of compensation, when sufficiently apologetic and restorative, right a wrong between victim and wrongdoer. From this, it would follow that, when a moral right is not publicly acknowledged, then any act of compensation will be incomplete and that it can only right a wrong when such rights have been acknowledged on a larger scale. This hypothesis would limit the strong compensation claim to the realm of established rights. I think this might be a plausible restriction, but I will not argue for it here.

\subsection{Apologetic Compensation vs. Compensation-plus-Apology.}


Let us now return to the objection raised at the end of section 3.0. This was the worry that there might not be any relevant difference between apologetic compensation and compensation-plus-apology, and that if apologetic compensation can repair moral wrongs qua compensation then so could compensation-plus-apology. I will address these two objections in turn.

What motivates the category of apologetic compensation is that nonapologetic compensation does not suffice on its own to repair moral wrongs since it does not address the wronging aspect (as argued in section 1). Furthermore, mere apology does not suffice to repair moral wrongs since verbal apologies could be found "too cheap" and without consequence. Both of these positions seem to be supported in the literature and intuitively plausible. What I also suggest is that the combination of the above two-a verbal apology plus a nonapologetic compensation-would not rule out each of these worries in the joint case. An apology could still be perceived as "cheap" even if there was a monetary compensation added to it but there was no action to bring about any change to the moral situation. An act of monetary compensation could still be perceived as unapologetic even if the right apologetic words were spoken. In fact, in the Bullingdon case, it seems that both verbal apology and full monetary compensation was offered-but without acknowledgement of wrong. I think this "cheapness" is not so much a case of the absence of money to back the apology up as it is an absence of an action that expresses a genuine regret and wish for things to be different strong enough to motivate action that makes that believable. If so, then it does not seem to be the combination of two things-something towards the material reparation and something towards the apology-that suffices to repair wrongs.

What I have argued is that it suffices to overwrite the wronging message with a compensatory act. This is then largely an expressive reparation. It could then be argued that it is the apologetic part that does the righting (and not the compensation). I think this is right. However, that righting could not occur by verbal apology. Rather, the righting must be expressed in an act of apologetic compensation such that one offers some service or good that expresses the intention that things be otherwise than they are as a result of the wrongful act. It is thus an apology that takes the form of compensation and alters the world in a 
particular way that does the righting. A verbal apology could be added to such an act to make the message more explicit and less prone to be misunderstood; however, this apology would not, strictly speaking, be necessary in order to right the wrong. Is this still an act of compensation? I would think so, since what is offered is not so much a verbal statement as an act offering a service or good to the victim of wrong, which offering is deliberately aimed at addressing the impacts of a previous wrong (and which thus, from an objective point of view, would look like things changing hands, services performed, and so on).

\section{Risks, Rights, and Compensation.}

Should compensation be sufficient to repair moral wrongs, then this could have interesting implications for risk ethics (see Hayenhjelm \& Wolff, 2012 for overview; for recent contributions see Kumar, 2015; Steigleder, 2016; Oberdiek, 2008; and Ferretti, 2016). A problem that has received a fair amount of attention in the literature is "the problem of paralysis" that arises for rights-based ethics (Hayenhjelm \& Wolff, 2012, for an overview, see also, e.g., Holm, 2017; McCarthy, 1997; Teuber, 1990). If there are individual rights not to have risks imposed upon one, then any action that imposes a risk on another would be impermissible. The problem is that many everyday activities impose a risk of some kind and would thus be impermissible (unless consented to). Furthermore, many risky activities affect anonymous others whose identity will not be known until harm occurs and whose consent cannot, therefore, be attained. Nozick (2006, pp.57-84) addressed this problem in Anarchy, State and Utopia. What he suggests is something like the following:

1. Person $\mathrm{Y}$ wants to do $\mathrm{A}$, where $\mathrm{A}$ is an activity that imposes a risk $\mathrm{R}$ on $\mathrm{X}$.

2. Given that $\mathrm{X}$ has a right not to have risks imposed (no matter its probability or degree of potential harm), $\mathrm{Y}$ is not permitted to do A (unless $\mathrm{X}$ consents).

3. The compensation solution is that $\mathrm{Y}$ is permitted to do $\mathrm{A}$ if $\mathrm{Y}$ ex ante commits to fully compensate $\mathrm{X}$ post ante for any harm that might result from $\mathrm{R}$.

Nozick's suggestion seems congenial: we only correct harm when harm is done. Actions are not prohibited on mere grounds of what could happen. Instead, 
it is the agent's commitment to post ante repair that determines an action's permissibility. For the tricky cases, such as those of small risks to large populations, this seems to be a promising way forward. However, this solution depends on the assumption that compensation can achieve full moral repair. I have argued above that compensation can right wrongs after they have occurred if they are sincerely regretted and come with an intention not to be repeated. This kind of compensation is not very helpful in terms of justifying risks for future harm. The only kind of compensation that can be offered before harm has occurred is a non-apologetic one. If the activity is controversial, this does not seem to offer a way out of consent. Non-apologetic compensation can perhaps offer a "good deal" that "tempts" a person to agree to a risk they otherwise would not have agreed to. But, on its own, it does not seem to justify risks. Thus, if we want to claim that impositions of risk constitute rights violations, then compensation cannot solve the problem of justification.

There is another point worth stating explicitly here. "Imposing a risk" does not typically refer to an activity with the end goal of increasing the probability of harm (the often-discussed cases of Russian roulette being, perhaps, the exception.) It is, rather, another name for the pursuit of some good that also has the negative side effect of increasing the probability of some harm. The question of justification for a risk depends on whether that good can be pursued in a less risky way or whether it can be abandoned without increasing some other risk. We have presumed that "imposing a risk" would violate a right to not be exposed to an avoidable risk of harm. But we need to say something more about the nature of this wrong. It might be helpful to think of the variety of ways in which we could wrong someone with regard to risk in a more specific manner. We could introduce a policy that imposed a risk that was far higher than it needed to be in order to save money on safety measures. We could introduce a new activity that proved very useful but would bring about irreversible damage and severe negative effects in the event of an accident-and so on. Note that such wrongs would apply to everyone exposed to the risks rather than just those that were also harmed by the risk.

Some such wrongs could be compensated for-apologetically-afterwards quite independently of any compensation of actual harm. In other words, what 
seemed like a simple wrong of "imposing a risk" could be divided into two kinds of wrong-doing: 1) exposing people to a new or greater risk; and 2) bringing about actual harm for a few as a result. Both of these wrongs could be compensated for apologetically afterwards, but again, compensation could not justify them in the first place.

But this is not the only function of compensation. Compensation can also redistribute the burdens and benefits of risks. Imagine a case where everyone has consented to a particular kind of activity as being worth the risks, but that some will inevitably be more exposed to the risks than others. Some individuals might, for example, live right next to a nuclear power plant and others very far from it. In such a case, we could compensate those that are more exposed and genuinely regret that we had to expose those individuals to more risks, but without us regretting the risky activity as such. To make such a partial regret sincere, we might have to ensure that other risky policies will not similarly expose those same individuals yet again and that there is an intention to let this higher risk be an exception.

It seems that the primary role for compensation is to redistribute benefits and burdens of risk impositions: either to make the impositions of risk such that individuals would consent to them (if compensated), or to make sure that the distribution of risks can be considered fair (and those at greater risk due to greater vulnerability are duly compensated). 5 This, however, is compensation in a rather different sense than that of righting wrongs. In other words, compensation cannot provide a general justification for risk imposition sufficient to solve the problem of reconciling risk impositions and individual rights. That is not to say that compensation cannot play any role with regard to the ethics of risk: it is only that such a role is more limited.

\section{References}


Brown, S.P. (2001). Punishment and the Restoration of Rights.

Punishment \& Society, 3(4), 485-500.

https://doi.org/10.1177/14624740122228384

Chapman, B. (1995). Wrongdoing, welfare, and damages: recovery for nonpecuniary loss in corrective justice. In D. Owen (Ed.), Philosophical foundations of tort law (pp. 409-425). Oxford: Oxford University Press.

Cohen, G.A. (2012). Rescuing Conservatism: A Defense of Existing Value. In Finding Oneself in the Other (pp. 143-174). Princeton: Princeton University Press.

Corlett, J.A. (2002). Wrongdoing, Reparations and Native Americans. In R. C. Roberts (Ed.) Injustice and Rectification (pp. 147-164). New York: Peter Lang Publishing.

Duff, R.A. (2001). Punishment, communication, and community. Oxford: Oxford University Press.

Feinberg, J. (1970a). Justice and Personal Desert. In Doing and Deserving (pp. 55-87). Princeton: Princeton University Press.

Feinberg, J. (1970b). The Expressive Function of Punishment. In Doing and Deserving (pp. 95-118). Princeton: Princeton University Press.

Ferretti, M.P. (2016). Risk impositions and freedom. Politics, Philosophy, and Economics, 15 (3):261-279.

http://journals.sagepub.com/doi/abs/10.1177/1470594X15605437

Gaus, G.F. (1991). Does compensation restore equality? In J.W. Chapman (Ed.) NOMOS XXXIII: Compensatory Justice (pp. 45-81). New York: New York University Press.

Gill, K. (2000). The moral functions of an apology. The Philosophical Forum 31(1): 11-27. http://onlinelibrary.wiley.com/doi/10.1111/o031806X.00025/full

Goodin, R. (1991). Theories of compensation. In R. Frey \& C. Morris (Eds.), Liability and Responsibility: Essays in Law and Morals (pp. 257-289). Cambridge: Cambridge University Press. 
Govier, T. \& Verwoerd, W. (2002). The promise and pitfalls of apology. Journal of Social Philosophy 33(1): 67-82. http://onlinelibrary.wiley.com/doi/10.1111/1467-9833.00124/full

Griseri, P. (1985). Punishment and Reparation. The Philosophical Quarterly, 35 (141), 394-413. Retrieved from: http://www.jstor.org/stable/2219474?seq=1\#page_scan_tab_contents

Hampton, J. (2007). Righting wrongs: The goal of retributivism. In D. Farnham (Ed.), The Intrinsic Worth of Persons: Contractarianism in Moral and Political Philosophy (pp. 108-150). Cambridge: Cambridge University Press.

Hayenhjelm, M. (2012). What is a fair distribution of risk? In S. Roeser, M Peterson, R Hillerbrand \& P. Sandin (Eds.) Handbook of Risk Theory (pp. 909929). Dordrecht: Springer Publisher. https://doi.org/10.1007/978-94-0071433-5_36

Hayenhjelm, M \& Wolff, J. (2012) The Moral Problem of Risk Impositions: A Survey of the Literature. European Journal of Philosophy, 20(S1): E26-E51. https://doi.org/10.1111/j.1468-0378.2011.00482.x

Hegel, G. (1973). Hegel's Philosophy of Right (T.M. Knox, translator). New York: Oxford University Press.

Holm, S. (2016). A Right Against Risk Imposition and the Problem of Paralysis. Ethical Theory and Moral Practice, 19 (4): 917-930. https://doi.org/10.1007/s10677-016-9697-6

Kumar, R. (2015). Risking and Wronging. Philosophy and Public Affairs, 43 (1): 27-51. http://onlinelibrary.wiley.com/doi/10.1111/papa.12042/full

Lazar, S. R. (2008). Corrective justice and the possibility of rectification. Ethical Theory and Moral Practice, 11(4), 355-368. https://doi.org/10.1007/s10677-008-9108-8

Marshall, S. (2001). Noncompensatable wrongs, or having to say you're sorry. In M.H. Kramer (Ed.), Rights, Wrongs and Responsibilities (pp. 209224). New York: Palgrave. 
McCarthy, D. (1997). Rights, explanation, and risks. Ethics, 107(2): 205225 .

http://www.journals.uchicago.edu/doi/abs/10.1086/233718?journalCode=et

Nozick, R. (2006 [1974]). Anarchy, State, and Utopia. Malden, MA: Blackwell Publishing.

Nozick, R. (1981). Philosophical Explanations. Cambridge, MA: Belnap Press, Harvard University Press.

Oberdiek, J. (2008). Towards a Right Against Risking. Law and Philosophy, 28(4): 367-392. https://doi.org/10.1007/s10982-0o8-9039-5

Radzik, L. (2004). Making amends. American Philosophical Quarterly 41(2): 141-154. Retrieved from: http://www.jstor.org/stable/20010149?seq=1\#page_scan_tab_contents

Railton, P. (1985). Lock, stock, and peril: Natural property rights, pollution, and risk. In M. Gibson (Ed.), To Breathe Freely: Risk, Consent and Air (pp. 89-123). Totowa, NJ: Rowman \& Allanheld.

Ripstein, A. (2006). Beyond the harm principle. Philosophy \& Public Affairs, 34 (3), 215-245.

https://doi.org/10.1111/j.1088-4963.2006.00066.x

Roberts, R.C. (2002). Justice and Rectification: A Taxonomy of Justice. In R. C. Roberts (Ed.), Injustice and Rectification (pp. 7-28). New York: Peter Lang.

Ronay, B. (2008, May 9). Young, rich and drunk. The Guardian. Retrieved from:

http://www.guardian.co.uk/education/2008/may/o9/oxbridgeandelitism.high ereducation.

Samuelson, W., \& Zeckhauser, R. (1988). Status quo bias in decision making. Journal of risk and uncertainty, 1(1), 7-59.

https://doi.org/10.1007/BFoo055564

Smith, N. (2008). I Was Wrong: The Meanings of Apologies. Cambridge: Cambridge University Press. 
Steigleder, K. (2016). Climate risks, climate economics, and the foundations of rights-based risk ethics. Journal of Human Rights 15 (2): 251271. http://dx.doi.org/10.1080/14754835.2015.1083849

Teuber, A. (1990). Justifying risk. Daedalus 119(4): 235-254. Retrieved from: http://www.jstor.org/stable/20025348.

Zimmerman, M.J. (1994). Rights, Compensation, and Culpability. Law and Philosophy 13(4): 419-450. https://doi.org/10.1007/BF02350478 